\title{
Roles for Pain Modulatory Cells during Micturition and Continence
}

\author{
Madelyn A. Baez, Thaddeus S. Brink, and Peggy Mason \\ Committee on Neurobiology and Department of Neurobiology, Pharmacology, and Physiology, University of Chicago, Chicago, Illinois 60637
}

We studied how the nervous system selects between noxious stimulus-evoked withdrawals and micturition, movements that are necessary for survival but use overlapping muscles and therefore cannot occur simultaneously. In lightly anesthetized rats, micturition was favored, because noxious stimulation never interrupted micturition, whereas withdrawals were suppressed during voiding. Neurons in the ventromedial medulla (VMM) are a major source of descending antinociceptive signals. To test whether VMM neurons support withdrawal suppression during micturition, the discharge of VMM neurons was recorded during continence and micturition. VMM cells that were inhibited (M-inh) or excited (M-exc) during micturition were observed. M-inh cells were excited by noxious cutaneous stimulation and thus are likely nociception facilitating, whereas M-exc cells were inhibited by noxious heat and are likely nociception inhibiting. The excitation of nociception-inhibiting M-exc and inhibition of nociception-facilitating M-inh cells predicts suppression of withdrawals during micturition. M-exc cells were typically silent before micturition, whereas most M-inh cells fired before micturition, suggesting that these cells may also play a preparatory role for micturition. To test this idea, we examined manipulations that either advanced or delayed the onset of micturition. Hypothalamic stimulation and noxious paw heat advanced micturition while exciting M-inh cells and inhibiting M-exc cells. In contrast, colorectal distension, a stimulus that delays micturition, inhibited M-inh cells and excited M-exc cells. These results suggest a model in which, during continence, VMM M-inh cells facilitate and M-exc cells inhibit bladder afferents, advancing micturition onset when M-inh cells are activated and delaying onset when M-exc cells are activated.

Key words: bladder; visceral; nociceptive modulation; electrophysiology; raphe magnus; rostral ventromedial medulla; RVM

\section{Introduction}

Micturition is critical for survival because urinary retention causes infections and, if unrelieved, eventually results in death. However, the motor act of micturition prevents an individual from making other movements such as escape, defecation, or mating. Therefore, animals initiate voiding only after maximizing their safety (Blok, 2002) and continue uninterrupted even when startled by unexpected stimuli. It is unclear whether micturition would be similarly uninterrupted by noxious stimulation that would typically elicit a protective withdrawal of the hind limb. To understand how the nervous system selects between protective and homeostatic motor patterns, we examined whether micturition and noxious stimulus-evoked withdrawals occur simultaneously or, if not, which prevails.

Normal micturition is under voluntary control and requires participation of neurons in the pontine micturition center (PMC) of the dorsolateral pons. PMC lesions block micturition and cause irreversible continence in the rat (Satoh et al., 1978). Bladder afferent input facilitates the initiation of micturition

Received March 29, 2004; revised Nov. 18, 2004; accepted Nov. 19, 2004.

This research was supported by National Institute of General Medical Sciences Grant TG32 GM07839 and the Christopher Reeve Paralysis Foundation. We thank Drs. Nino Ramirez and Cliff Ragsdale for helpful comments on this manuscript and M.M. for inspiration.

Correspondence should be addressed to Peggy Mason, Department of Neurobiology, Pharmacology, and Physiology, University of Chicago, MC 0926, 947 East 58th Street, Chicago, IL 60637. E-mail: p-mason@uchicago.edu. DOI:10.1523/JNEUROSCI.3536-04.2005

Copyright $\odot 2005$ Society for Neuroscience $\quad$ 0270-6474/05/250384-11\$15.00/0
(Noto et al., 1991). Injection of pseudorabies virus, a transsynaptic retrograde marker that marks central autonomic control pathways (Strack et al., 1989a,b), into the bladder, the external urethral sphincter, or urethra (Nadelhaft and Vera, 1995, 1996, 2001; Vizzard et al., 1995) labels neurons in PMC, the caudal ventrolateral periaqueductal gray (PAGvl), and the hypothalamic medial preoptic nucleus (MPO). Both PAGvl and MPO project densely to PMC (Valentino et al., 1994; Ding et al., 1998, 1999; Taniguchi et al., 2002). Positron emission tomography studies of humans reveal that both MPO and PAGvl are more active during micturition than during continence and may play roles in the initiation of voiding (Blok et al., 1997; Blok and Holstege, 1998).

The ventromedial medulla (VMM) includes raphe magnus (RM) and the adjacent nucleus reticularis magnocellularis (NRMC) (after Newman, 1985) and comprises a major source of descending modulatory input to spinal nociceptive neurons in the superficial spinal dorsal horn (Basbaum and Fields, 1984; Fields et al., 1991; Sandkuhler, 1996; Mason, 2001; Gebhart, 2004). Medullary modulation of nociceptive transmission is nonserotonergic (Aimone and Gebhart, 1986; Matos et al., 1992; Sorkin et al., 1993; Gao et al., 1997, 1998), mediated by two nonserotonergic VMM cell types (Fields et al., 1983; Barbaro et al., 1986; Mason, 1997; Gao and Mason, 2000). OFF cells are inhibited by noxious cutaneous stimulation, are excited by opioids, and are thought to suppress cutaneous nociceptive transmission, whereas $\mathrm{ON}$ cells are excited by noxious cutaneous stimulation, inhibited by opioids, and likely facilitate cutaneous nociceptive 
transmission. To test whether ON and OFF cells modulate noxious stimulus-evoked withdrawals during micturition, we recorded their activity during continence and voiding.

The VMM modulates visceral as well as cutaneous inputs (Chapman et al., 1985; Tattersall et al., 1986; Holt et al., 1991; Knuepfer and Holt, 1991; Zhuo and Gebhart, 2002; Zhuo et al., 2002). Because bladder contractions increase in frequency and size with increasing bladder pressure, require supraspinal input, and are inhibited by RM stimulation (Sugaya et al., 1998), RM may inhibit bladder afferent input. Therefore, we examined the effect of manipulating VMM cell activity on the initiation of micturition.

\section{Materials and Methods}

Subjects and surgery. All procedures were approved by the Animal Care and Use Committee of the University of Chicago. Male Sprague Dawley rats ( $n=100$, 250-500 gm; Charles River, Portage, MI) were treated with atropine sulfate $(40 \mu \mathrm{g}$ in $0.1 \mathrm{ml}$, s.c.) and anesthetized with halothane ( $n=87)$ or urethane $(n=13 ; 1.2 \mathrm{gm} / \mathrm{kg}$, i.p.). The invasive surgery required for these experiments necessitated the use of anesthesia. Because urethane often suppressed withdrawal reactions, halothane was used in most experiments. At the concentration of halothane used $(0.8-1.0 \%)$, both micturition and withdrawal reactions occur reliably. Furthermore, VMM cell activity is qualitatively similar during light anesthesia and in the absence of anesthesia (Leung and Mason, 1999). Halothane was administered through a nose cone adapted for the stereotaxic and was maintained at $1.8-2.0 \%$ in oxygen for the surgery. A catheter was inserted into the femoral artery to record blood pressure. Craniotomies were made to allow for the introduction of recording electrodes into the medulla in all animals and stimulating electrodes into the hypothalamus, the latter in 50 animals.

Cystometry was performed using a catheter introduced through the dome of the bladder so that (1) we could visually confirm fluid expulsion and (2) we could identify the expelled fluid as either urine or semen. Ureter ligation is likely noxious, and therefore the ureters were left intact (Laird et al., 1996). A saline-filled catheter (PE50) with a side port connected to a pressure transducer for monitoring vesicular pressure was inserted into the bladder dome and fixed in place. The bladder was periodically distended with a bolus of sterile saline (25-100 $\mu \mathrm{l})$ maintained at room temperature.

Needle electrodes were placed into the flexor muscles of the hind limb to record noxious heat-evoked withdrawals and into the bulbospongiosus muscles to record voiding episodes. After the surgery, all animals received $10 \mathrm{ml}$ of Ringer's solution subcutaneously. The halothane concentration was lowered to $0.8-1.0 \%$, and the animal was allowed to equilibrate for $30-60 \mathrm{~min}$.

Electrophysiological methods. Tungsten metal microelectrodes (A-M Systems, Pullman, WA) were lowered into the brainstem [posterior $(\mathrm{P})$, $10.5-11.8 \mathrm{~mm}$ from bregma; lateral (L), 0.0-1.0 mm; ventral (V), 8.510.5 from cerebellar surface]. Neurons were isolated by their spontaneous activity. The unit waveform was acquired at $20 \mathrm{kHz}$ by a CED $1401+$ interface (Cambridge Electronics Design, Cambridge, UK). Spike2 acquisition software (Cambridge Electronics Design) stored the time of the spike, the spike type, and 36 digitized points from the waveform. Individual waveforms were discriminated off-line using template-matching software.

Cutaneous noxious stimulation. Cells were tested for their responses to noxious paw heat. Paw heat was applied using a peltier device (Yale Instrumentation, New Haven, CT) placed on the footpad and toes of the hindpaw. The paw was affixed to the peltier platform so that it was exposed to the full duration of the stimulus. Each heat stimulus consisted of a $2 \mathrm{sec}$ ramp from $32^{\circ} \mathrm{C}$ to $56^{\circ} \mathrm{C}$ and a $4 \mathrm{sec}$ plateau at $56^{\circ} \mathrm{C}$. The peltier platform then ramped back down to $32^{\circ} \mathrm{C}$ over the course of 4 sec. Between thermal stimuli, the peltier platform was maintained at $32^{\circ} \mathrm{C}$.

Hypothalamic stimulation. Stimulation electrodes were placed bilaterally into the hypothalamus [P, 0.4-2.0 mm from bregma; $\mathrm{L}, 0.5-1.0 \mathrm{~mm}$; V, 8.0-9.5 from cerebellar surface (Paxinos and Watson, 1986)]. The stimulation protocol consisted of either continuous stimulation or a train (1 sec on-off) of pulses (200 $\mu \mathrm{sec})$ at $200-400 \mu \mathrm{A}$ and $40-50 \mathrm{~Hz}$ for up to $30 \mathrm{sec}$.

Experimental protocol. After isolation of a unit, repeated (two to five) trials of paw heat, bladder distension, and hypothalamic stimulation were presented. All stimuli were separated by intervals of 3-5 min. The recording site for at least one cell per animal was labeled by injection of hyperpolarizing current ( $4 \mathrm{~min}, 20 \mu \mathrm{A})$.

Urethral stimulation. In a separate cohort of rats $(n=4)$, a small incision was made in the abdomen, and a saline-filled catheter was inserted into the urethra from the bladder and secured with a tight suture around the bladder neck. VMM cells were isolated by their spontaneous discharge and characterized by their responses to noxious paw heat and saline infusion through the urethra.

Response to colorectal distension. In an additional cohort of rats $(n=$ 26), a balloon was placed in the colon and rectum $(9 \mathrm{~cm})$, and EMG electrodes were placed in the abdominal musculature. In these animals, the bladder was not catheterized nor were electrodes placed in the hypothalamus. These rats were equilibrated to a halothane concentration of $0.8 \%$ and given $10 \mathrm{cc}$ of Ringer's solution subcutaneously. Under these conditions, micturition occurred spontaneously at least once during an experiment.

Cells were isolated by their spontaneous discharge and characterized by their responses to noxious paw heat and colorectal distension as described in a separate publication (Brink and Mason, 2004). When the abdominal musculature spontaneously contracted in the absence of a colorectal distension, the experimenter visually confirmed that urine was being expelled. The discharge of 33 neurons during one to three trials of spontaneous micturition was studied.

VMM stimulation. To determine the effect of VMM activation on bladder pressure and bulbospongiosus activity, continuous stimulation $(50-150 \mathrm{~Hz}, 200 \mu \mathrm{sec}$ pulses, $50-300 \mu \mathrm{A})$ for up to $30 \mathrm{sec}$, at the recording site of each cell, was administered at low and high bladder pressures.

To test whether VMM stimulation suppressed noxious stimulationevoked withdrawals, continuous stimulation was administered starting 1-2 sec before the onset of the noxious stimulus and continuing for $10 \mathrm{sec}$.

Histology. Animals were overdosed with 5\% halothane and then perfused with a fixative containing $4 \%$ paraformaldehyde and $7 \%$ sucrose in a 0.1 M PBS. The brain was removed, postfixed for $4-12 \mathrm{hr}$, and then cryoprotected by immersion in $30 \%$ sucrose in $0.1 \mathrm{M}$ PBS. Coronal sections $(50 \mu \mathrm{m})$ were cut on a freezing microtome. Sections were mounted on gelatin-coated slides and stained with cresyl violet. Recording and stimulating sites were plotted onto standard sections. Unmarked sites were located by their stereotaxic distance from marked recording sites.

Cellular analysis. Although VMM cells with a slow and regular pattern of discharge that are highly likely to be serotonergic (Mason, 1997; Li and Bayliss, 1998; Wang et al., 2001) were not studied, an algorithm that physiologically identifies serotonergic and nonserotonergic cells was used to ensure that all studied cells were indeed nonserotonergic (Mason, 1997). A previously described quantitative method was then used to classify all cells by their response to noxious paw heat as ON, OFF, or NEUTRAL (Leung and Mason, 1998).

Micturition and withdrawal analyses. The onset and offset of each micturition episode was determined by the onset and offset of oscillations in vesicular pressure. In animals without a bladder catheter, micturition episodes were marked by the occurrence of abdominal muscle activation.

The flexor EMG was full-wave rectified and integrated for $10 \mathrm{sec}$ after the onset of the thermal stimulus. All withdrawals were then normalized to the median withdrawal recorded during continence for each animal.

Statistics. Each variable is expressed as a mean \pm SE. Statistical tests were performed using Microsoft (Redmond, WA) Excel.

\section{Results}

\section{Micturition characteristics}

Animals continued to produce urine because they were well hydrated and their ureters were not ligated. Therefore, micturition occurred "spontaneously" (i.e., $>200 \mathrm{sec}$ after any manipulation) at an average rate of once every 30-40 min. As described previously, the expulsion phase of micturition in the rat is 
A

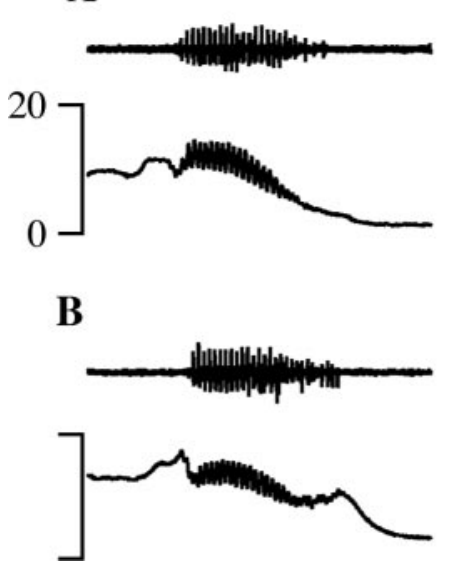

C

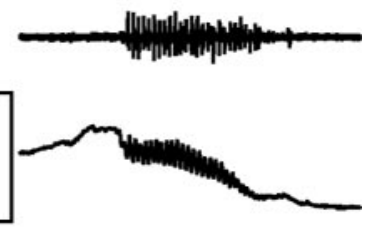

D

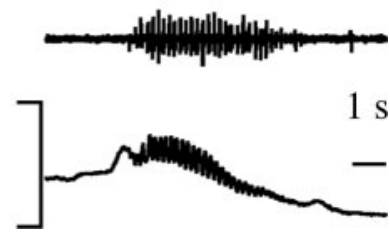

Figure 1. Spontaneous and evoked micturition episodes are marked by bursting activity in the bulbospongiosus EMG (top trace) and simultaneous oscillations in vesicular pressure (bottom trace). $A$, A spontaneous micturition episode. $B, A$ micturition episode evoked 5 sec after injection of $0.1 \mathrm{ml}$ of saline. C, A micturition episode evoked $24 \mathrm{sec}$ after stimulation of MPO.D, A micturition episode evoked 6 sec after noxious heat was applied to the hindpaw. All recordings come from the same animal, and all records are 10 sec in length (see time bar in D).

marked by oscillations in vesicular pressure (Kruse et al., 1990; Matsuura et al., 1998). During these pressure oscillations, the bulbospongiosus muscle contracted in bursts (Fig. 1) and the expulsion of urine was visually confirmed. Spontaneous micturition episodes typically included a single bout of bulbospongiosus bursting, with a mean duration of $6.2 \pm 0.5 \mathrm{sec}$ (Fig. $1 A$ ). Micturition also occurred at short latency (i.e., within $200 \mathrm{sec}$ ) after infusion of saline $(25-100 \mu \mathrm{l})$ into the bladder (Fig. 1B). The mean latency from bladder distension to the onset of urine expulsion was $25.8 \pm 3.3 \mathrm{sec}$, and the mean duration of the ensuing micturition was $5.8 \pm 0.6 \mathrm{sec}$.

Bilateral stimulation in the anterior hypothalamus, at sites concentrated in but not restricted to the medial preoptic region, evoked micturition at a mean latency of $47.5 \pm 6.0 \mathrm{sec}$ (Fig. 1C). The most efficacious stimulation sites were the medial preoptic area (MPA) and the MPO (Fig. 2). Stimulation within MPA evoked micturition in $41 \%$ of the trials (53 of 130) at a mean latency of $44 \pm 5 \mathrm{sec}$. Stimulation within MPO evoked micturition in $47 \%$ of the trials ( 41 of 87 ) at a mean latency of $54 \pm 19$ sec. Other sites with fewer than 30 stimulation trials that elicited micturition included the horizontal and vertical limbs of the diagonal band and the stria part of the preoptic area. The stimulation sites in 10 animals were not recovered. Additionally, in 14 animals, only one of the two stimulation sites was recovered.

Micturition was also observed after noxious thermal (Fig. 1D) or mechanical stimulation of the paws, as well as light mechanical stimulation of the glans. Micturition was evoked by only a minority ( 159 of $1154 ; 14 \%$ ) of noxious stimulation trials but often resulted when the stimulation coincided with a relatively full bladder. Micturition followed these somatosensory stimuli at mean latencies of $35.1 \pm 3.6 \mathrm{sec}$ (noxious heat, 139 of $794 ; 18 \%$ ) (Fig. $1 D$ ) or $19.9 \pm 6.6 \mathrm{sec}$ (noxious pinch, 20 of $360 ; 6 \%$ ). These latencies are 50 - to 100 -fold shorter than the average interval between spontaneous durations, making it likely that the stimuli "evoked" the micturition episodes. The duration of micturition episodes evoked by cutaneous stimulation averaged $5.3 \pm 0.6 \mathrm{sec}$ when after pinch and $5.7 \pm 0.7 \mathrm{sec}$ when after noxious heat.

The duration of urine expulsion was not different across types of micturition, either spontaneous or evoked (ANOVA; $p=$ 0.99). Furthermore, there were no obvious differences in the pat-
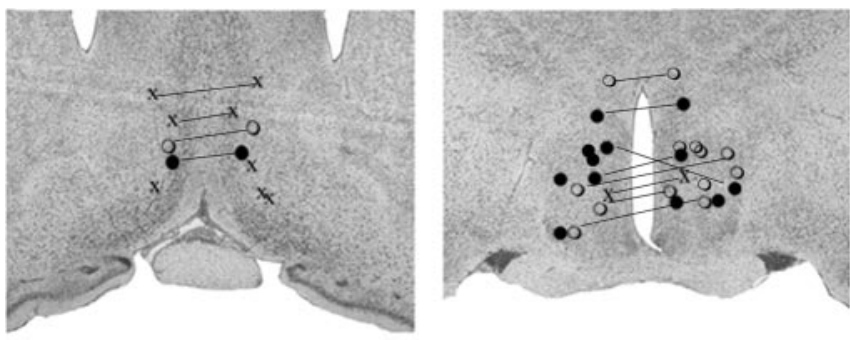

0.2
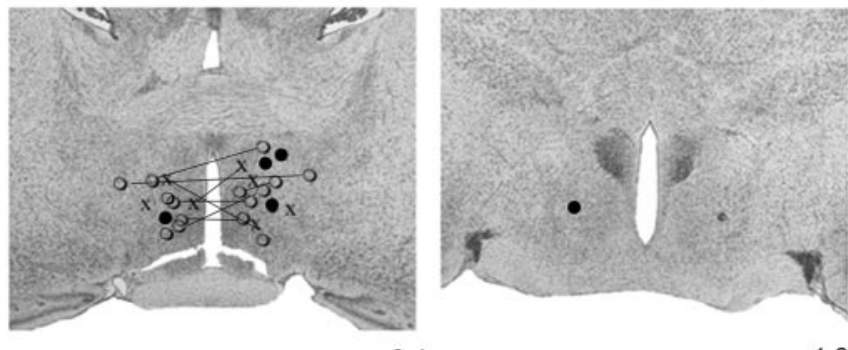

$-0.4$

Figure 2. Hypothalamic sites that elicited micturition in $50-100 \%$ of the stimulation trials are marked with filled circles. Sites that elicited micturition in $<50 \%$ of the stimulation trials are marked with open circles, and sites ineffective in eliciting micturition are marked with " $x$ ". All stimulation was bilateral. Lines join sites that were located in the same plane and stimulated together. Sites that were stimulated together but were not located in the same plane are denoted by the same symbol but are not joined by lines. Of the 40 recovered sites, 26 were recovered bilaterally, and only one side was recovered in the remaining 14 cases. The level of each photomicrograph relative to bregma is listed to the right.

tern of bulbospongiosus bursting and bladder pressure oscillations between spontaneous micturitions and those evoked by bladder distension, hypothalamic stimulation, or cutaneous stimulation (Fig. 1).

The variability in micturition duration was larger between animals than within animals. For instance, the micturition durations of one animal that voided eight times were within a $2.6 \mathrm{sec}$ range. The average difference between each animal's shortest and longest micturition episodes was $4.2 \pm 2.9 \mathrm{sec}$, whereas the average micturition durations across animals ranged over $>11 \mathrm{sec}$.

\section{Effect of noxious stimulation on micturition}

Micturition episodes that overlapped with a noxious heat stimulus, for a minimum of $100 \mathrm{msec}$, were compared with those that did not. In the animal illustrated in Figure $3 A$, micturition duration was long, averaging $12.7 \mathrm{sec}$. In the spontaneous micturition episode illustrated in Figure 3A2, the bulbospongiosus muscle (middle trace) contracted and the vesicular pressure (bottom trace) oscillated for $15.3 \mathrm{sec}$. When paw heat was applied $4.2 \mathrm{sec}$ into the spontaneous micturition illustrated in Figure $3 A 3$, voiding continued for another $9 \mathrm{sec}$, for a total urine expulsion time of $13.2 \mathrm{sec}$. This difference of $2.1 \mathrm{sec}$ is within the average range of micturition durations from individual animals $(4.2 \pm 2.9 \mathrm{sec}$; see above). In the animal illustrated in Figure $3 B$, micturition duration averaged $5.7 \mathrm{sec}$. The difference $(1.8 \mathrm{sec})$ between the micturition durations in the presence ( $7.4 \mathrm{sec}$ ) (Fig. 3B3) and absence $(5.6 \mathrm{sec})$ (Fig. 3B2) of noxious heat stimulation of the paw was again less than the average within-animal variation. Furthermore, note that, in the example illustrated in Figure $3 A$, the micturition in the absence of noxious stimulation was slightly longer than that which overlapped with noxious stimulation, whereas the reverse was true in the example illustrated in Figure $3 B$.

The persistence of micturition after noxious stimulation was a 
A1

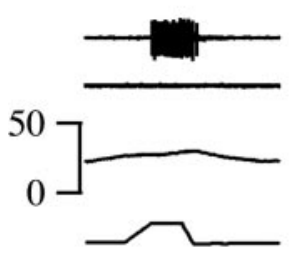

A2

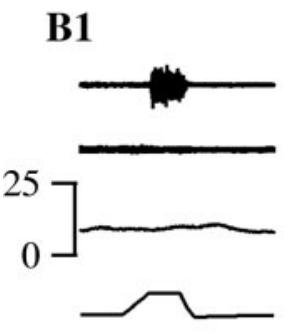

B2
A3
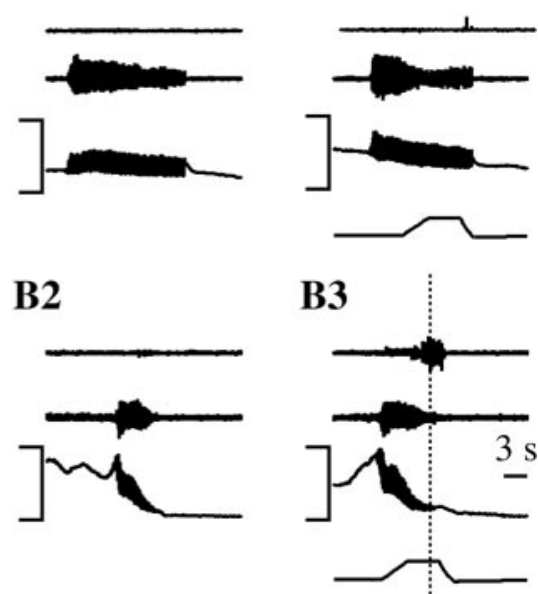

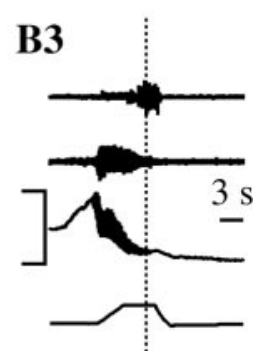

Figure 3. Paw heat did not change the duration of micturition, but micturition suppressed withdrawals evoked by noxious paw heat. Representative records from two different animals $(A, B)$ are shown. The traces from top to bottom are flexor EMG, bulbospongiosus EMG, vesicular pressure, and paw stimulus temperature ( 1 and 3 only). Noxious paw heat during continence $(A 1, B 1)$ and micturition $(A 3, B 3) . A 2, B 2$, A spontaneous micturition episode. The dotted line in $B 3$ marks the end of urine expulsion. The time bar in $B 3$ applies to all traces.

consistent finding. When noxious hindpaw heat was presented during micturition, micturition always continued without interruption (Fig. 3A2,A3, B2,B3); we never observed a micturition that stopped during application of noxious paw heat. Across all experiments, there was no difference in the durations of micturition episodes that occurred in the absence $(5.7 \pm 0.6 \mathrm{sec})$ (Fig. $4 A$, dashes) or presence $(5.9 \pm 0.5 \mathrm{sec}$ ) (Fig. $4 A$, open circles) of noxious paw heat (Mann-Whitney test; $p=0.15$ ). Because only the duration of urine expulsion was measured, it is possible that other measures of micturition were different in the presence and absence of noxious stimulation.

\section{The motor reaction to paw heat during continence and micturition}

The ramp phase of the noxious heat stimulus was $2 \mathrm{sec}$ in duration, the plateau was $4 \mathrm{sec}$, and $4 \mathrm{sec}$ was required to cool the paw back to the holding temperature. Therefore, the stimulus was longer in duration than most micturition episodes; only 39 of 324 micturition episodes were longer than the $10 \mathrm{sec}$ duration (Fig. $3 A 2, A 3)$.

The withdrawal reaction to a noxious heat stimulus was greatly attenuated and often eliminated when the withdrawal overlapped with a micturition episode. The long-duration micturition episodes in the animal illustrated in Figure $3 \mathrm{~A}$ allowed for total overlap between urine expulsion and noxious stimulation. During continence in this animal, noxious paw heat elicited a withdrawal (top trace) at a latency of $3.4 \mathrm{sec}$ (Fig. 3A1). However, when the noxious heat stimulus overlapped with a spontaneous micturition, the same noxious stimulus failed to elicit any withdrawal (Fig. 3A3). In the animal illustrated in Figure 3B, the overlap between micturition and noxious stimulation was less than complete (Fig. 3B3). In this case, the withdrawal was greatly reduced but not eliminated when compared with the withdrawal observed during continence. The latency to withdrawal was 3.6 sec during continence (Fig. 3B1) and $4.7 \mathrm{sec}$ during micturition (Fig. 3B3). During continence, the normalized (see Materials and Methods) magnitude of the withdrawal in Figure $3 B 1$ was 1.2. In

A

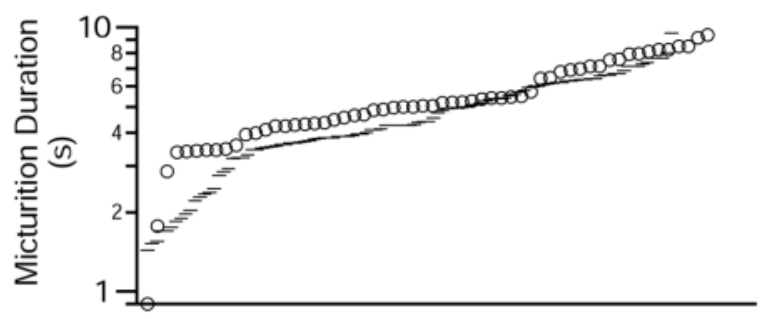

B

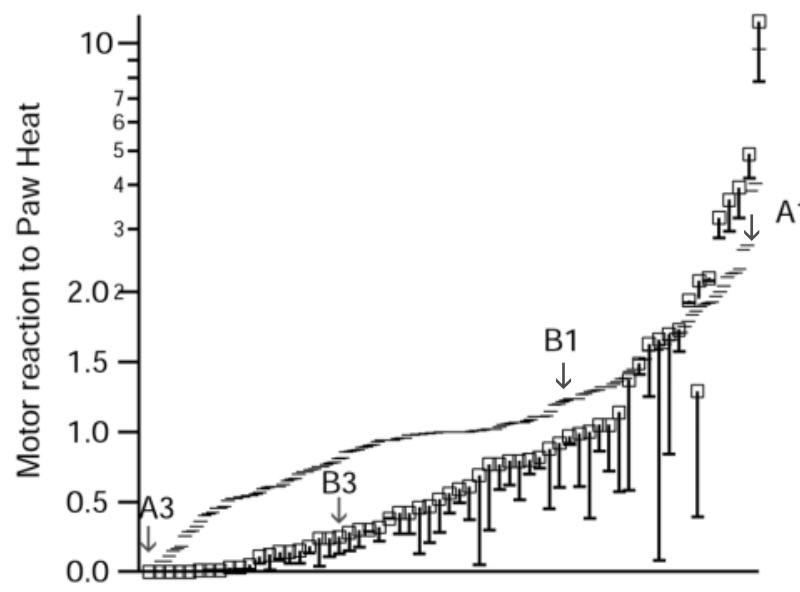

Figure 4. Semilog plots of the effects of paw heat on micturition duration $(A)$ and of micturition on paw-withdrawal magnitude $(B)$. $A$, Micturition duration was not different between episodes that overlapped with paw heat (squares) and those that did not (dashes). $B$, The magnitude of the noxious heat-evoked withdrawal was significantly less when the withdrawal overlapped with a micturition episode than when it did not (dashes). The total magnitude of each withdrawal that overlapped with micturition is shown by the squares. The magnitude of the withdrawal that occurred during the micturition is shown by the dash connected to each square.

contrast, when overlapping with micturition, the withdrawal had a magnitude of 0.5 (Fig. 3B3). Furthermore, most of the withdrawal evoked during micturition occurred after the completion of urine expulsion (Fig. 3B3, right of the dotted line).

To analyze the effect of micturition on noxious heat-evoked paw withdrawals for the entire sample, withdrawals that occurred entirely during continence were compared with withdrawals that overlapped with urine expulsion, for $\geq 100 \mathrm{msec}$. The duration of overlap between withdrawal and urine expulsion was modest, averaging only $3.7 \pm 0.3 \mathrm{sec}$. During continence, $>90 \%$ of paw heat trials elicited a motor reaction, resulting in a failure rate of only $9.5 \%$ (15 of 158). When the paw heat reaction period overlapped with a micturition, the failure rate was significantly greater ( 24 of $61 ; 39.3 \% ; \chi^{2}$ test; $\left.p<0.001\right)$. Furthermore, withdrawals that occurred during micturition were significantly smaller than those that occurred during continence (Fig. 4B) (Mann-Whitney test; $p=0.0001$ ). When withdrawals did occur during micturition, they were concentrated after or before bulbospongiosus bursting (Fig. 3B3). The magnitude of the withdrawal that occurred in trials with overlap is shown in open boxes in Figure $4 B$, whereas the magnitude of the withdrawal that occurred specifically during the overlap with micturition is shown by the dashes connected to the boxes. Thus, withdrawal reactions were smaller during micturition and, when they occurred, were concentrated before or after urine expulsion. In some cases, noxious paw heat evoked a prolonged EMG reaction that was transiently suppressed during micturition and resumed after 
completion of micturition (data not shown). In summary, noxious stimulation elicited little or no hind limb withdrawal during micturition, whereas micturition was unaffected by noxious paw heat or the resulting withdrawal.

\section{Characterization of recorded cells}

To investigate whether VMM neurons contribute to the suppression of heat-evoked withdrawals during micturition, we recorded from 84 VMM cells that changed their discharge during micturition. All cells were clearly nonserotonergic. The mean background discharge rate for all cells was $9.2 \pm 0.7$ (SE) spikes/sec. Most cells $(n=60)$ discharged in bursts with a mean interstimulus interval coefficient of variation $\left(\mathrm{CV}_{\text {ISI }}\right)$ of $6.05 \pm 0.71$ and a mean discharge rate of $6.0 \pm 0.7 \mathrm{~Hz}$. The remaining cells $(n=24)$ did not burst $\left(\mathrm{CV}_{\text {ISI }}<1\right)$ and had a mean $\mathrm{CV}_{\text {ISI }}$ of $0.43 \pm 0.05$ and a mean discharge rate of $19.8 \pm 1.9 \mathrm{~Hz}$ (minimum, 9.7 Hz). Thus, no cell fired in the slow and steady manner characteristic of serotonergic cells in anesthetized and unanesthetized animals (Heym et al., 1982; Auerbach et al., 1985; Fornal et al., 1985; Mason, 1997). Recorded cells were concentrated in RM $(n=36)$ and NRMC $(n=34)$ (Fig. 5).

\section{Cellular discharge during micturition}

Almost all VMM cells changed their discharge specifically during the period of urine expulsion of micturition (83 of 84), either increasing $(n=30)$ or decreasing $(n=53)$ their discharge rate. One cell changed its discharge during both the bladder contraction preceding urine expulsion and during urine expulsion itself.

Cells that were inhibited during urine expulsion were termed M-inh cells (Figs. 6, 7A). As seen in the example shown in Figure $6 A$, these cells stopped firing during the bursts of bulbospongiosus muscle contractions and the coincident oscillations in bladder pressure. In cases when the animal voided and the cell was not previously firing, the cell continued to not fire (Fig. $6 \mathrm{~B}$ ). M-inh cells fired $53 \pm 11$ fewer spikes during urine expulsion than before voiding, representing a decrease in firing rate of $6.5 \pm 0.8$ spikes/sec (Fig. 7C).

Cells that were excited during urine expulsion were termed $\mathrm{M}$-exc cells (Figs. 7B, 8). As seen in Figure 8, an increase in M-exc discharge was observed regardless of whether the cell was firing before the micturition. When an M-exc cell was firing before micturition, the cell increased its discharge further during bulbospongiosus muscle contractions and the coincident oscillations in bladder pressure (Fig. $8 B$ ). M-exc cells $(n=30)$ fired $64 \pm 15$ spikes more during urine expulsion than before voiding, representing a mean increase in firing rate of $11.5 \pm 2.2 \mathrm{spikes} / \mathrm{sec}$ (Fig. 7C). There were no obvious differences between the discharge of either $\mathrm{M}$-exc or M-inh cells during spontaneous micturition (Fig. $8 A$ ) or micturition evoked by bladder distension (Figs. 6A, 8C), hypothalamic (Figs. 6B, 8B), or cutaneous stimulation.

The discharge of one cell started to increase when the bladder pressure was high but before the start of the expulsion phase and declined to zero within $1.5 \mathrm{sec}$ of the start of voiding (data not shown), resembling the excited-inhibited cells observed previously in decerebrate cats (Sugaya et al., 2003).

\section{The cellular responses of M-exc and M-inh cells to noxious heat}

To investigate a possible association between nociceptive modulatory cell class and the discharge pattern during micturition, cells were further characterized by their response to noxious paw heat. $\mathrm{M}$-inh cells were excited by noxious paw heat by an average of
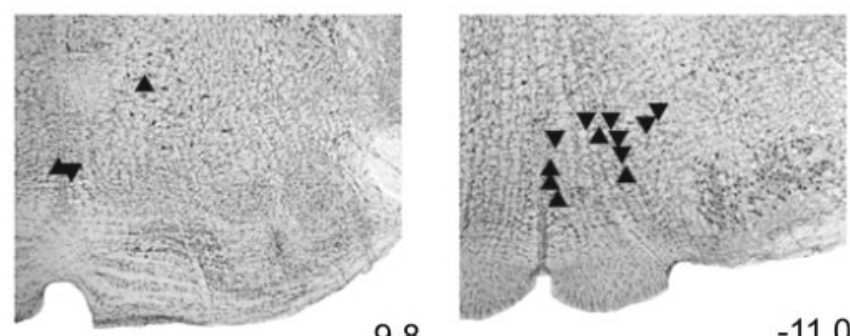

$-9.8$
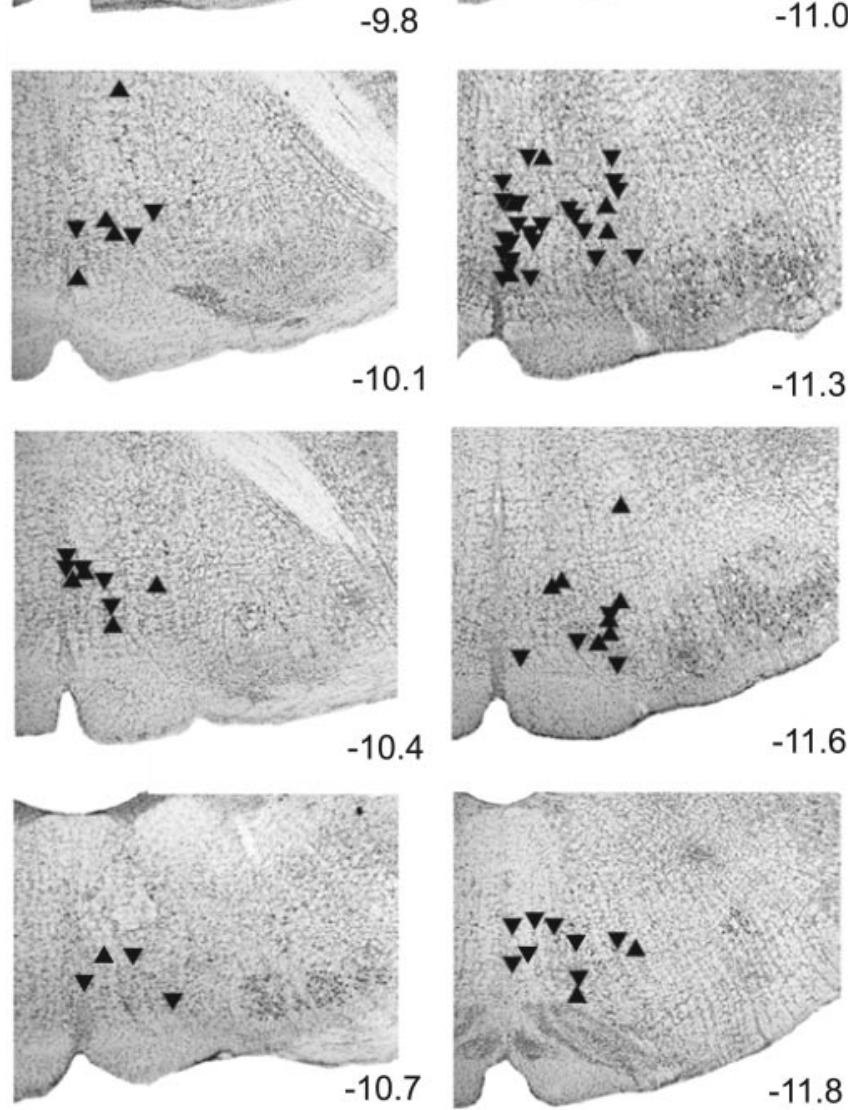

Figure 5. Recording sites were concentrated within RM and NRMC. The level of each photomicrograph relative to bregma is listed to the right. Sites where M-inh $(n=53)$ and M-exc $(n=30)$ cells were recorded are marked by downward and upward triangles, respectively.

$88 \pm 11$ spikes in $10 \mathrm{sec}$ (Figs. 6C, 7C). M-exc cells were inhibited by noxious paw heat by an average of $65 \pm 18$ spikes in $10 \mathrm{sec}$ (Figs. $7 C, 8 D$ ). In addition to these population trends, the response to noxious heat was significant in most individual cases, with 19 of $31(61 \%)$ M-exc cells inhibited by noxious paw heat (and therefore OFF cells) and 40 of 53 (75\%) M-inh cells excited by noxious paw heat (and therefore ON cells) (Leung and Mason, 1998). The association between micturition-related discharge pattern and nociceptive modulatory cell class was significant ( $\mathrm{p}$ $<0.001 ; \chi^{2}$ test). The pattern of VMM cell discharge during micturition (excitation of nociceptive-inhibitory cells and inhibition of nociceptive-facilitatory cells) predicts the observed suppression of noxious stimulation-evoked withdrawals during micturition (see Fig. 12A).

The excited-inhibited cell mentioned above was unaffected by noxious thermal stimulation. M-inh cells $(n=3)$ were excited and M-exc cells $(n=2)$ were inhibited by glans stimulation.

\section{Responses to bladder distension and urethral stimulation}

VMM cells with micturition-related discharge had a nearly constant firing rate throughout urine expulsion, a period when 


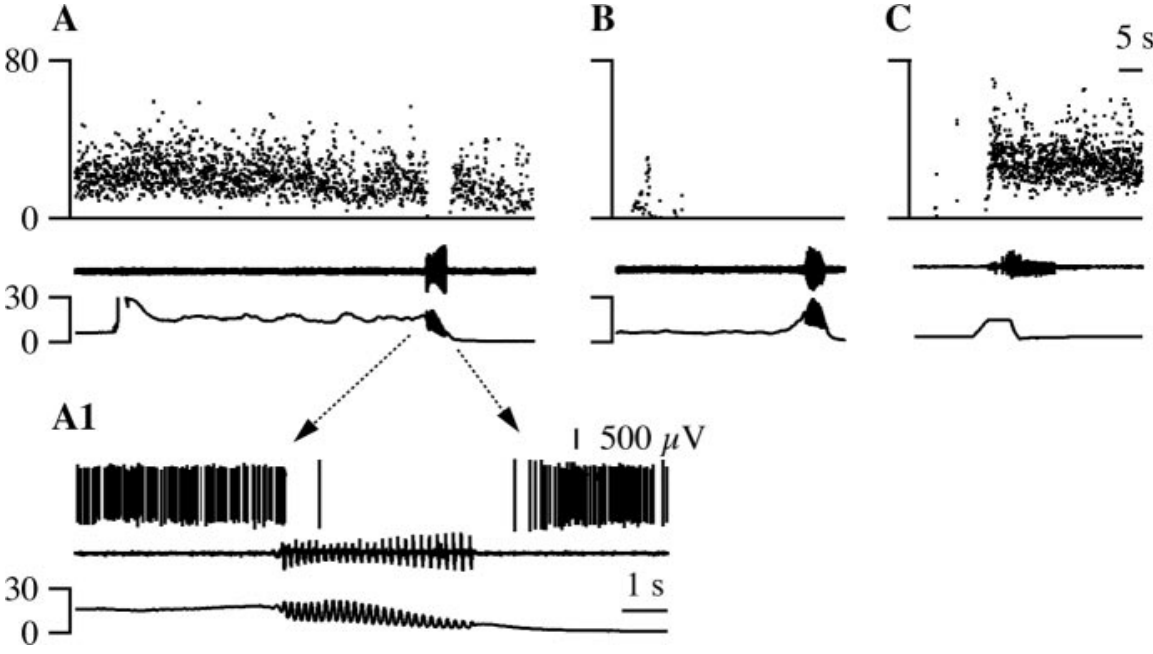

Figure 6. An M-inh cell. $A$, This cell decreased its instantaneous firing frequency (top trace) during volume-evoked micturition marked by bulbospongiosus muscle contractions (middle trace) and vesicular oscillations (bottom trace). A1, The portion indicated by the dashed lines with arrows in $A$ is shown at an expanded time scale. The two bottom traces are the same as in $A$; the top trace shows raw waveform data from the cell recording. $B$, When this cell was not firing, a spontaneous micturition episode had no effect on its extracellularly recorded discharge. C, This cell was excited by noxious paw heat (bottom trace) that elicited a paw withdrawal (middle trace). The time bar in $C$ applies to $A-C$ and that in $A 1$ to $A 1$ alone.
A

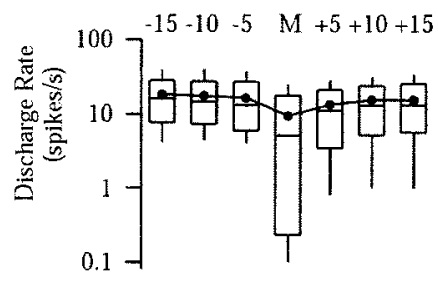

C

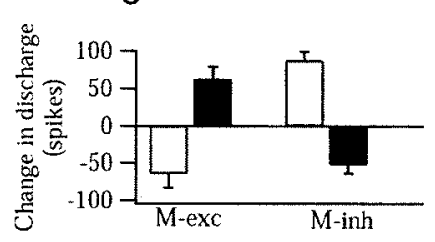

B

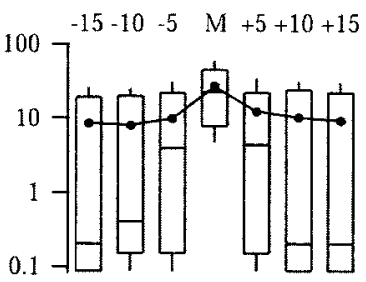

Figure 7. M-inh and $\mathrm{M}$-exc cells respond in opposing directions to micturition and noxious cutaneous heat. $A, B$, Box plots of the activity in spikes per second of $\mathrm{M}$-inh $(A)$ and $\mathrm{M}$-exc $(B)$ cells before, during, and after micturition on a semilog plot. For three sequential $5 \mathrm{sec}$ bins before and after, the start and end times, respectively, of the 5 -sec bins, relative to the onset and offset of micturition, are listed at the top. The bin marked " $M$ " is of variable duration and marks the period of vesicular oscillations and bulbospongiosus bursting. At each time point, the 10,25, 50 (median), 75, and 90\% percentile values are shown by the rectangles and extending bars. Filled circles joined by a line mark the mean at each time point. C, The mean change in discharge rate from baseline values in $\mathrm{M}$-exc (left) and $\mathrm{M}$-inh (right) cells during micturition (filled bars) and in response to noxious paw heat (open bars).

vesicular pressure declined from a peak value to near zero, suggesting that the discharge was not attributable to bladder afferent input. In support of this idea, no M-inh ( 0 of 34) or M-exc ( 0 of 18) cell responded to bladder distension (Figs. $6 \mathrm{~A}, 8 \mathrm{C})$. M-inh $(0$ of 18) and $\mathrm{M}$-exc ( 0 of 12 ) cells also failed to change their discharge during subthreshold bladder contractions that were not accompanied by bulbospongiosus contractions or urine expulsion (data not shown). Furthermore, VMM cells did not respond to saline infusion through the urethra $(n=6)$. This evidence suggests that the micturition-related discharge of M-inh and
M-exc cells is not a sensory response to bladder or urethral afferent input.

Discharge of the excited-inhibited cell mentioned above increased its rate as the vesicular pressure increased and peaked at the maximal vesicular pressure before becoming silent just after the onset of micturition. The discharge rate of this cell did not consistently change during contractions that did not lead to micturition.

\section{Effect of VMM stimulation on vesicular pressure}

As a crude test of whether VMM cells contribute to the motor command for micturition, the recording site was stimulated. VMM stimulation at intensities above 50 $\mu \mathrm{A}$ typically has nociception-inhibitory rather than nociception-facilitatory effects (Zhuo and Gebhart, 1997). Indeed, VMM stimulation suppressed the motor withdrawal from noxious paw heat in $75 \%$ of 32 trials (data not shown). This may reflect the preferential, although surely not exclusive, excitation of nociception-inhibitory cells (Hentall et al., 1984). VMM stimulation at the recording sites of M-inh and M-exc cells failed to evoke micturition in $98 \%$ of 149 trials (data not shown). This evidence suggests that VMM is unlikely to generate the micturition motor pattern, consistent with previous evidence that the pons, rather than the medulla, initiates micturition (Barrington, 1925).

\section{VMM activity before micturition}

Although VMM stimulation did not evoke micturition, it did suppress on-going, subthreshold bladder contractions (data not shown), as has been reported previously (Sugaya et al., 1998). Bladder contractions become larger and occur more frequently with increasing vesicular pressure and are dependent on descending input from the brainstem (Sugaya et al., 1998). These findings led us to consider whether VMM neurons play a preparatory role in the initiation of micturition, perhaps by modulating bladder afferent input. To test whether VMM neurons influence the timing of micturition, we first examined the activity of $\mathrm{M}$-inh and M-exc cells for the $15 \mathrm{sec}$ preceding micturition. Most M-inh cells ( 88 of 100 ) fired at $>5 \mathrm{~Hz}$ before micturition, whereas only onethird of M-exc cells (22 of 65) did so (Fig. 7A,B) (p <0.001; $\chi^{2}$ test). This supports the idea that, during continence, $M$-exc cells facilitate and M-inh cells inhibit the initiation of micturition.

\section{VMM activity during advances in micturition}

When micturition occurred spontaneously, vesicular pressure gradually approached the micturition threshold (Fig. 9A1, dotted line) and was at near threshold levels for $\sim 1$ min before the initiation of micturition (Fig. 9A2). In contrast, micturition episodes evoked by hypothalamic stimulation occurred even when vesicular pressure was below the micturition threshold (Fig. 9B). To further test whether the activity of VMM cells modulates the timing of micturition, the effect of hypothalamic stimulation on VMM cells was determined. Hypothalamic stimulation initially excited 23 of 40 M-inh cells and inhibited 9 of 13 M-exc cells (Fig. 10) regardless of whether stimulation evoked micturition. In cases when stimulation evoked micturition, the initial response patterns were reversed when urine expulsion actually began. Thus, $\mathrm{M}$-inh cells were initially ex- 
cited by hypothalamic stimulation and stopped firing at the onset of bulbospongiosus muscle contractions, whereas M-exc cells were initially inhibited but then increased their discharge at the onset of urine expulsion. These results are consistent with the idea that the hypothalamic stimulationevoked excitation of M-inh cells and inhibition of M-exc cells advances the onset of micturition by facilitating and disinhibiting bladder afferent input, respectively (see Discussion and Fig. 12B).

Noxious stimulation, like hypothalamic stimulation, excited M-inh cells (Fig. 11B1), inhibited M-exc cells (Fig. $11 A 1)$, and evoked micturition at short latency (Figs. 11A2,B2) and at a vesicular pressure below the micturition threshold (Fig. 9C). Micturition-related discharge prevailed over heat-evoked responses such that M-exc cells were less inhibited and M-inh cells less excited by noxious heat when micturition resulted (Fig. $11 A, B$ ). Thus, both hypothalamic and noxious stimulation excite $M$-inh cells and inhibit M-exc cells while hastening the switch from continence to micturition.

\section{VMM cell responses to}

\section{colorectal distension}

Because colorectal stimulation causes profound and long-lasting urinary retention (Kock and Pompeius, 1963; Floyd et al., 1982; Pescatori, 1999), we hypothesized that such stimulation would excite M-exc and inhibit M-inh cells during continence. In these experiments, the bladder was not cannulated, and contraction of the superficial abdominal muscles coincided with visible urine expulsion. It is interesting to note that the abdominal muscles contracted in bursts $(\sim 7 \mathrm{~Hz})$ similar to those seen in the bulbospongiosus muscle and distinct from the pattern evoked by noxious colorectal distension (Brink and Mason, 2004). M-inh cells were inhibited by colorectal distension (mean, $-21 \pm 17$ spikes in $20 \mathrm{sec}$ ), and M-exc cells were excited (mean, $125 \pm 44$ spikes in $20 \mathrm{sec}$ ).

Figure $11 C$ shows an M-exc cell (Fig. 11C1) that was excited by colorectal distension (Fig. 11C2). Similarly, Figure $11 \mathrm{D}$ shows an M-inh cell (Fig. 11D1) that was inhibited by colorectal distension (Fig. 11D2). When considered individually, 5 of $11 \mathrm{M}$-inh cells were significantly inhibited by colorectal distension, and 11 of 12 $\mathrm{M}$-exc cells were significantly excited. These results are consistent with the idea that activation of $\mathrm{M}$-inh cells advances and activation of M-exc cells delays the onset of micturition (Fig. 12 B).

\section{Discussion}

Noxious stimulus-evoked withdrawal suppression during micturition

We show that micturition continues even in the presence of noxious input. In contrast, high-threshold stimuli disrupt or termi-

A1 alone.
B
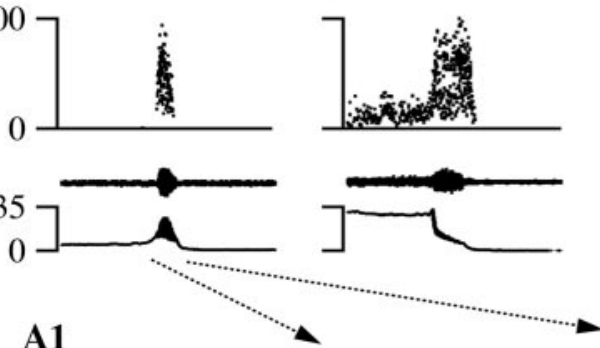

Figure 8. An M-exc cell. The same conventions as in Figure 6 are used. The discharge of this cell increased during spontaneous $(A, A 7)$ and volume-evoked ( $C$ ) micturition episodes. $B$, A micturition episode that occurred 93 sec after MPA stimulation. $D$, This $M$-exc cell was inhibited by noxious paw heat that elicited a paw withdrawal. The time bar in $D$ applies to $A-D$ and that in $A 1$ to $A 1$

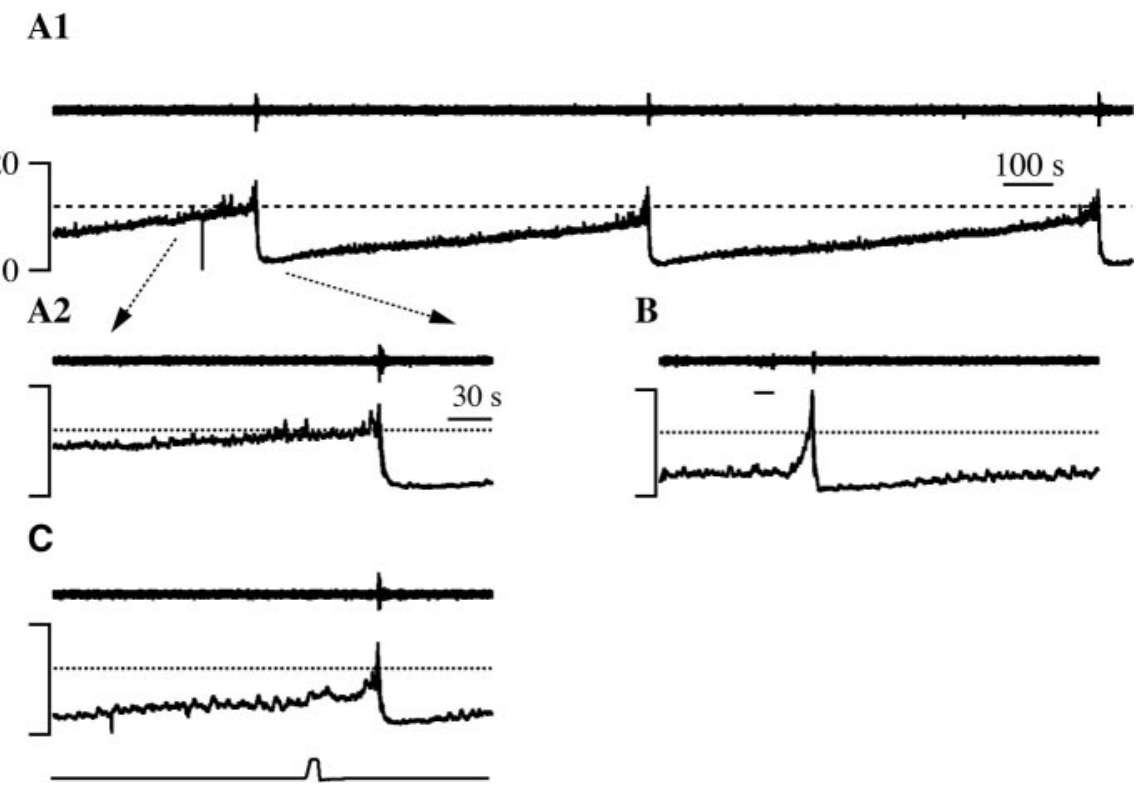

Figure 9. Hypothalamic stimulation-evoked $(B)$ and noxious heat-evoked $(C)$ micturitions occurred at lower vesicular presdotted line in this and other panels. Part of the first micturition, marked by the dotted arrows, is expanded in A2. B, MPA stimulation (line under EMG trace) evoked a micturition. C, Noxious paw heat (bottom trace) evoked a micturition. The time bar in $A 1$ applies to $A 1$ alone, and that in $A 2$ applies to $A 2, B$, and $C$.

nate other active movements such as locomotion or mastication (Forssberg, 1979; Lund et al., 1981, 1983; Haraguchi et al., 1994). These conflicting findings may result from the location of the noxious stimulus relative to the motor pattern. In the present study, a hindpaw, which is engaged for the micturition posture in awake but not anesthetized rats, was stimulated. In the studies cited above, stimulation was applied to a structure involved in the movement, such as the paw in the case of locomotion. Thus, noxious input at the site of an active movement may halt movement, whereas more distant noxious inputs may leave active movements unaltered. Alternatively, perhaps only critical movements, such as micturition, persist in the face of noxious stimulation.

Not only does micturition persist in the face of noxious stim- 
A1

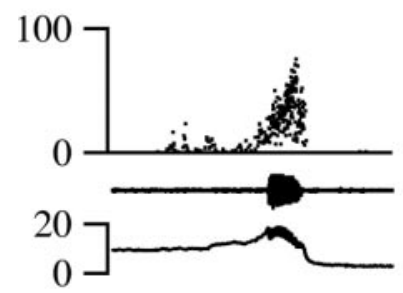

B1

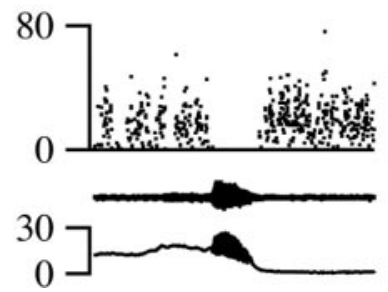

A2

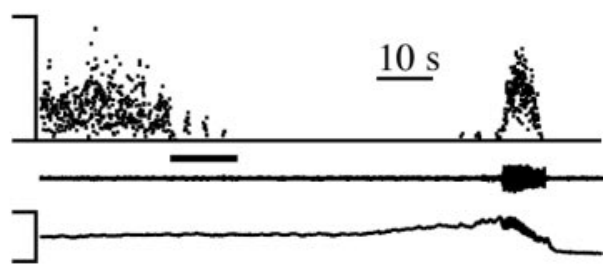

B2

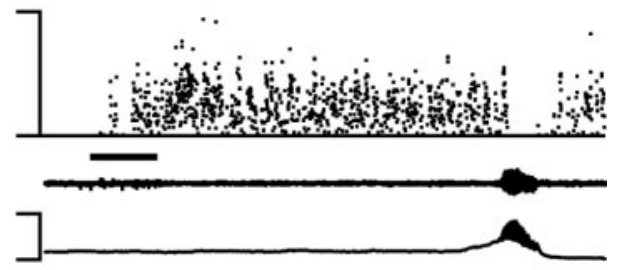

Figure 10. Hypothalamic stimulation inhibits M-exc cells and excites M-inh cells. In all panels, the traces are as follows, from top to bottom: instantaneous discharge, bulbospongiosus EMG, and vesicular pressure. The line under the discharge trace marks the time of hypothalamic stimulation. $A$, Discharge of an M-exc cell during a spontaneous micturition (A1) and a micturition evoked by MPO stimulation (A2). $B$, The activity of an M-inh cell during spontaneous micturition (B1) and during MPA stimulation that evoked micturition (B2). The time bar in $A 2$ applies to all traces.

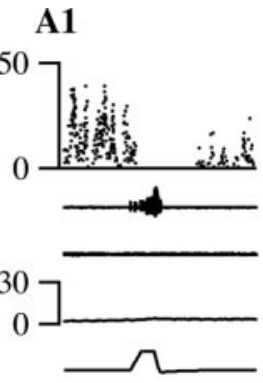

A2

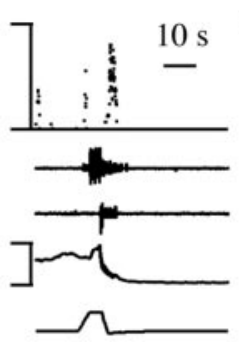

B1

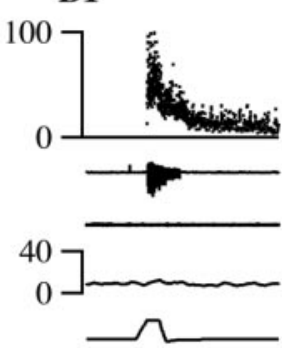

C1

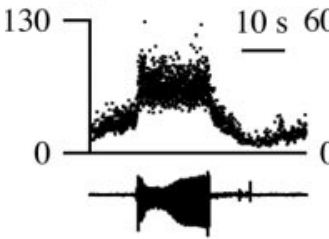

D1

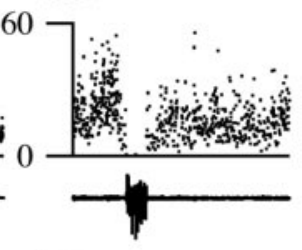

C2

D2
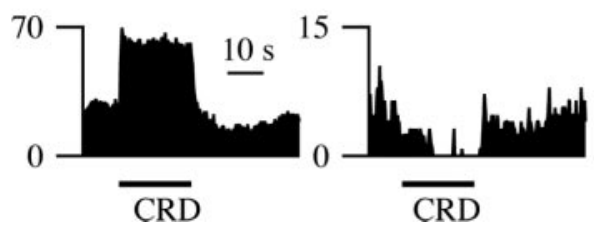

Figure 11. The responses of $M-\operatorname{exc}(A, C)$ and $M$-inh $(B, D)$ cells to stimuli that advance $(A, B)$ or delay $(C, D)$ micturition. $A, B$, The discharge (top trace) of M-inh $(A)$ and $M$-exc $(B)$ cells in response to noxious paw heat (bottom trace) that did $(A 2, B 2)$ or did not $(A 1, B 1)$ elicit micturition. Micturition was marked by vesicular pressure oscillations (fourth trace) and bursting of the bulbospongiosus muscle (middle trace). The withdrawal response from noxious heat is marked by flexor EMG activity (second trace). $C, D$, Responses of M-exc $(C)$ and M-inh (D) cells to colorectal distension. C1, D1, Instantaneous firing frequency of VMM cells during micturition marked by contraction of superficial abdominal muscles (bottom trace). (2, D2, The mean response of VMM cells to three (C2) or five (D2) trials of 20 -sec, $60 \mathrm{mmHg}$ colorectal distension (CRD, line under trace).

ulation, but noxious stimulus-evoked withdrawal movements are suppressed during micturition. This suppression may be one component of a more generalized sensory suppression associated with micturition. During micturition relative to continence, syn-
B2

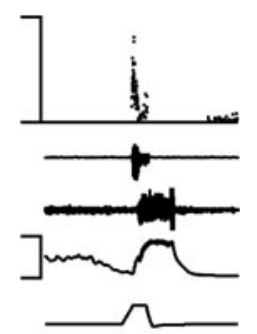

aptic potentials evoked by electrical stimulation of cutaneous and muscle afferents are depressed in motoneurons that innervate hind limb withdrawal muscles (Fedirchuk et al., 1994). Because the responses to the same motoneurons to monosynaptic muscle afferent input were unchanged, the suppression of lumbosacral afferent information during micturition appears to act at a site presynaptic to the motoneuron, possibly on an interneuron. Consistent with this idea, neurons in the sacral dorsal and intermediate gray, including interneurons that receive group II muscle afferent input, are inhibited during micturition (Buss and Shefchyk, 2003).

VMM involvement in micturitionassociated withdrawal suppression Neurons that are excited, inhibited, or unaffected during urine expulsion have been observed in the cat (Chandler et al., 1994; Sugaya et al., 2003), but the responses of such cells to noxious stimulation, and therefore their nociceptive modulatory roles, have not been described previously. We show that M-exc cells are inhibited by noxious stimulation and therefore comprise a subset of nociceptive-inhibitory OFF cells. Similarly, M-inh cells are excited by noxious stimulation and therefore are a subset of nociceptive-facilitatory ON cells. This pattern of VMM cell discharge during micturition predicts the observed suppression of noxious stimulus-evoked withdrawals (Fig. 12A). VMM cells are likely to exert these effects directly through their projections to the sacral and lumbar dorsal and intermediate gray (Basbaum et al., 1978; Basbaum and Fields, 1979; Watkins et al., 1980; Masson et al., 1991; Fields et al., 1995).

$\mathrm{M}$-inh cell inhibition and M-exc cell excitation persist throughout bulbospongiosus muscle contraction, while the bladder empties and bladder pressure decreases to near zero. Confirming that VMM cell discharge is not related to bladder pressure, VMM cells with micturitionrelated discharge did not respond to bladder distension or change their discharge during bladder contractions that were not accompanied by urine expulsion. Thus, VMM cells are either responsible for the micturition motor command or receive corollary discharge from neurons that initiate micturition. Because VMM stimulation fails to elicit micturition or to excite pelvic nerve efferents (McMahon and Spillane, 1982; Johnson and Hubscher, 1998), we favor the latter possibility. PMC sends few if any projections to VMM (Loewy et al., 1979; Abols and Basbaum, 1981; Hermann et al., 1997), but PAGvl and MPO project strongly (Basbaum et al., 1978; Van 
Bockstaele et al., 1991; Murphy et al., 1999). Thus, VMM may receive micturition-related corollary discharge from suprapontine neurons that also project to PMC and not from PMC itself (Ding et al., 1998).

Suppressing noxious stimulus-evoked withdrawals during micturition allows the hind limbs to maintain the posture required for micturition but leaves an animal vulnerable to attack. Therefore, animals check their environment carefully before initiating micturition (Blok, 2002). Reflexes evoked by low-threshold muscle and cutaneous afferents are suppressed during locomotion and mastication (Forssberg, 1979; Lund et al., 1981, 1983; Haraguchi et al., 1994), and the same may occur during micturition. Suppression of low-intensity sensory information that could trigger movements, such as stepping or orienting, during micturition is advantageous because it facilitates complete and uninterrupted voiding. Because VMM cells respond to unexpected innocuous stimuli as strongly as to noxious stimuli in the unanesthetized rat (Leung and Mason, 1999), they may modulate low-threshold as well as noxious sensory input to the dorsal horn during micturition.

\section{Hypothalamic-evoked micturition}

Although others have demonstrated hypothalamic stimulation-evoked bladder contractions (Gjone, 1966; Rocha et al., 2004), our demonstration of hypothalamic stimulation-evoked micturition (confirmed by urine expulsion, vesicular pressure oscillations, and bulbospongiosus bursting) is novel. M-inh cells were excited and M-exc cells were inhibited by hypothalamic stimulation, regardless of whether stimulation evoked micturition. The long latency of hypothalamic-evoked micturition and the independence of the VMM response from the behavioral effect of stimulation suggest that hypothalamic neurons elicit micturition through a polysynaptic circuit with a low safety factor. Because VMM cells responded to hypothalamic stimulation with a different discharge pattern than evident during micturition, the direct source of corollary discharge to VMM cells likely arises from a source caudal to the hypothalamus. As detailed above, PAGvl is a more likely source of input to VMM than is PMC.

\section{VMM modulation of micturition onset}

Under conditions of natural filling, vesicular pressure does not rise between micturition episodes (Matsuura and Downie, 2000). Vesicular pressure is thus not a function of vesicular volume but of the elastic state of the detrusor muscle (Klevmark, 2002). The compliance of the bladder in turn determines the firing rate of bladder afferents that convey "fullness" information. Thus, the finding that void volumes for individual humans and rats vary by more than an order of magnitude across micturition episodes (Haas et al., 1997; Mattsson et al., 2003) suggests neural modulation of detrusor compliance and/or bladder afferent input. VMM neurons are likely one source of such modulation because VMM stimulation suppresses spontaneous subthreshold bladder contractions that are greater at increasing volumes (Sugaya et al., 1998) and inhibits resting activity in pelvic parasympathetic nerves to the bladder (McMahon and Spillane, 1982).

We propose a different role for VMM neurons during continence than during micturition (Fig. 12B). During continence, activity in M-inh cells, corresponding to a subset of ON cells, is predicted to facilitate bladder afferent input to sacral and pontine micturition centers. Simultaneously, inhibition of M-exc cells, a subset of OFF cells, will disinhibit bladder afferent input. Micturition centers would interpret the combined result of such facilitation and disinhibition as a fuller bladder, resulting in voiding of a relatively small volume. In the same vein, inhibition of $\mathrm{M}$-inh cells and excitation of $\mathrm{M}$-exc cells by continencepromoting stimuli such as colorectal distension predict reduced afferent input to micturition centers and therefore delayed voiding of a greater volume. In support of M-exc cells having a suppressive effect on bladder afferent input, administration of $\mu$-opioid receptor agonists into the PAG excites OFF cells (Cheng et al., 1986) and causes urinary retention (Matsumoto et al., 2004).

Micturition is a rare event but occurs at high incidence and with the largest void volumes after arousal from sleep (Haas et al., 
1997; Mattsson et al., 2003). This fits well with our proposed model and the activity of nonserotonergic VMM cells across sleep-wake states (Leung and Mason, 1999). After sleep, the tonic discharge of OFF cells, including M-exc cells, would inhibit bladder afferent input to central micturition centers and thereby delay micturition. After awakening, $\mathrm{ON}$ cells, including $\mathrm{M}$-inh cells, become active and OFF cells fall silent, resulting in the facilitation and disinhibition of bladder input to central micturition centers and immediate micturition. In this light, it is interesting that lesions of the hypothalamus, the most likely source of staterelated input to VMM cells, commonly lead to nocturnal enuresis (Andrew and Nathan, 1964; Andrew et al., 1966), a specific dysfunction in the state-dependent control of the switch from continence to micturition.

\section{Conclusions}

We propose different roles for VMM neurons during continence and micturition. During continence, $\mathrm{M}$-exc activity and M-inh inactivity is hypothesized to promote continued storage, whereas the reciprocal discharge pattern hastens the switch from continence to micturition. However, during micturition, the modulatory effect of VMM cells on bladder afferent activity is shunted, possibly by an intervening interneuron. Similarly, Ia inhibitory input to motoneurons is occluded by simultaneous input from motor cortex (Kudina et al., 1993). Thus, once the motor program for micturition begins, central pattern generator activity dominates and VMM modulatory influences on neurons in the sacral micturition center are overwhelmed, ensuring that voiding continues to completion. In contrast, the modulatory influence of VMM on nociceptive cutaneous input remains strong during micturition, resulting in suppression of movements evoked by noxious stimulation.

\section{References}

Abols IA, Basbaum AI (1981) Afferent connections of the rostral medulla of the cat: a neural substrate for midbrain-medullary interactions in the modulation of pain. J Comp Neurol 201:285-297.

Aimone LD, Gebhart GF (1986) Stimulation-produced spinal inhibition from the midbrain in the rat is mediated by an excitatory amino acid neurotransmitter in the medial medulla. J Neurosci 6:1803-1813.

Andrew J, Nathan PW (1964) Lesions of the anterior frontal lobes and disturbances of micturition and defaecation. Brain 87:233-262.

Andrew J, Nathan PW, Spanos NC (1966) Disturbances of micturition and defaecation due to aneurysms of anterior communicating or anterior cerebral arteries. J Neurosurg 24:1-10.

Auerbach S, Fornal C, Jacobs BL (1985) Response of serotonin-containing neurons in nucleus raphe magnus to morphine, noxious stimuli, and periaqueductal gray stimulation in freely moving cats. Exp Neurol 88:609-628.

Barbaro NM, Heinricher MM, Fields HL (1986) Putative pain modulating neurons in the rostral ventral medulla: reflex-related activity predicts effects of morphine. Brain Res 366:203-210.

Barrington FJF (1925) The effect of lesion of the hind- and mid-brain on micturition in the cat. Quart J Exptl Physiol 15:81-102.

Basbaum AI, Fields HL (1979) The origin of descending pathways in the dorsolateral funiculus of the spinal cord of the cat and rat: further studies on the anatomy of pain modulation. J Comp Neurol 187:513-531.

Basbaum AI, Fields HL (1984) Endogenous pain control systems: brainstem spinal pathways and endorphin circuitry. Annu Rev Neurosci 7:309-338.

Basbaum AI, Clanton CH, Fields HL (1978) Three bulbospinal pathways from the rostral medulla of the cat: an autoradiographic study of pain modulating systems. J Comp Neurol 178:209-224.

Blok BF (2002) Central pathways controlling micturition and urinary continence. Urology 59:13-17.

Blok BF, Holstege G (1998) The central nervous system control of micturition in cats and humans. Behav Brain Res 92:119-125.

Blok BF, Willemsen AT, Holstege G (1997) A PET study on brain control of micturition in humans. Brain 120:111-121.
Brink TS, Mason P (2004) Role for raphe magnus neuronal responses in the behavioral reactions to colorectal distension. J Neurophysiol 92:2302-2311.

Buss RR, Shefchyk SJ (2003) Sacral dorsal horn neurone activity during micturition in the cat. J Physiol (Lond) 551:387-396.

Chandler MJ, Oh UT, Hobbs SF, Foreman RD (1994) Responses of feline raphespinal neurons to urinary bladder distension. J Auton Nerv Syst 47:213-224.

Chapman CD, Ammons WS, Foreman RD (1985) Raphe magnus inhibition of feline T1-T4 spinoreticular tract cell responses to visceral and somatic inputs. J Neurophysiol 53:773-785.

Cheng ZF, Fields HL, Heinricher MM (1986) Morphine microinjected into the periaqueductal gray has differential effects on 3 classes of medullary neurons. Brain Res 375:57-65.

Ding YQ, Wang D, Nie H, Guan ZL, Lu BZ, Li JS (1998) Direct projections from the periaqueductal gray to pontine micturition center neurons projecting to the lumbosacral cord segments: an electron microscopic study in the rat. Neurosci Lett 242:97-100.

Ding YQ, Wang D, Xu JQ, Ju G (1999) Direct projections from the medial preoptic area to spinally-projecting neurons in Barrington's nucleus: an electron microscope study in the rat. Neurosci Lett 271:175-178.

Fedirchuk B, Downie JW, Shefchyk SJ (1994) Reduction of perineal evoked excitatory postsynaptic potentials in cat lumbar and sacral motoneurons during micturition. J Neurosci 14:6153-6159.

Fields HL, Bry J, Hentall I, Zorman G (1983) The activity of neurons in the rostral medulla of the rat during withdrawal from noxious heat. J Neurosci 3:2545-2552.

Fields HL, Heinricher MM, Mason P (1991) Neurotransmitters in nociceptive modulatory circuits. Annu Rev Neurosci 14:219-245.

Fields HL, Malick A, Burstein R (1995) Dorsal horn projection targets of $\mathrm{ON}$ and OFF cells in the rostral ventromedial medulla. J Neurophysiol 74:1742-1759.

Floyd K, McMahon SB, Morrison JF (1982) Inhibitory interactions between colonic and vesical afferents in the micturition reflex of the cat. J Physiol (Lond) 322:45-52.

Fornal C, Auerbach S, Jacobs BL (1985) Activity of serotonin-containing neurons in nucleus raphe magnus in freely moving cats. Exp Neurol $88: 590-608$.

Forssberg H (1979) Stumbling corrective reaction: a phase-dependent compensatory reaction during locomotion. J Neurophysiol 42:936-953.

Gao K, Mason P (2000) Serotonergic raphe magnus cells that respond to noxious tail heat are not ON or OFF cells. J Neurophysiol 84:1719-1725.

Gao K, Kim YH, Mason P (1997) Serotonergic pontomedullary neurons are not activated by antinociceptive stimulation in the periaqueductal gray. J Neurosci 17:3285-3292.

Gao K, Chen DO, Genzen JR, Mason P (1998) Activation of serotonergic neurons in the raphe magnus is not necessary for morphine antinociception. J Neurosci 18:1860-1868.

Gebhart GF (2004) Descending modulation of pain. Neurosci Biobehav Rev 27:729-737.

Gjone R (1966) Excitatory and inhibitory bladder responses to stimulation of "limbic", diencephalic and mesencephalic structures in the cat. Acta Physiol Scand 66:91-102.

Haas M, Kluppel AC, Moolenaar F, Meijer DK, de Jong PE, de Zeeuw D (1997) Urine collection in the freely moving rat: reliability for measurement of short-term renal effects. J Pharmacol Toxicol Methods 38:47-51.

Haraguchi N, Yamada Y, Furusawa H, Matsuo K, Oi K, Sato T, Mizuno A (1994) Variation of the jaw-opening reflex during spontaneous mastication in rabbits. Brain Res Bull 35:93-95.

Hentall ID, Zorman G, Kansky S, Fields HL (1984) An estimate of minimum number of brain stem neurons required for inhibition of a flexion reflex. J Neurophysiol 51:978-985.

Hermann DM, Luppi PH, Peyron C, Hinckel P, Jouvet M (1997) Afferent projections to the rat nuclei raphe magnus, raphe pallidus and reticularis gigantocellularis pars alpha demonstrated by iontophoretic application of choleratoxin (subunit b). J Chem Neuroanat 13:1-21.

Heym J, Steinfels GF, Jacobs BL (1982) Activity of serotonin-containing neurons in the nucleus raphe pallidus of freely moving cats. Brain Res 251:259-276.

Holt IL, Akeyson EW, Knuepfer MM (1991) Medial medullary contribution to tonic descending inhibition of visceral input. Am J Physiol 261:R727-R737. 
Johnson RD, Hubscher CH (1998) Brainstem microstimulation differentially inhibits pudendal motoneuron reflex inputs. NeuroReport 9:341-345.

Klevmark B (2002) Volume threshold for micturition. Influence of filling rate on sensory and motor bladder function. Scand J Urol Nephrol Suppl 210:6-10.

Knuepfer MM, Holt IL (1991) Effects of electrical and chemical stimulation of nucleus raphe magnus on responses to renal nerve stimulation. Brain Res 543:327-334.

Kock NG, Pompeius R (1963) Inhibition of vesical motor activity induced by anal stimulation. Acta Chir Scand 126:244-250.

Kruse MN, Noto H, Roppolo JR, de Groat WC (1990) Pontine control of the urinary bladder and external urethral sphincter in the rat. Brain Res 532:182-190.

Kudina L, Ashby P, Downes L (1993) Effects of cortical stimulation on reciprocal inhibition in humans. Exp Brain Res 94:533-538.

Laird JM, Roza C, Cervero F (1996) Spinal dorsal horn neurons responding to noxious distension of the ureter in anesthetized rats. J Neurophysiol 76:3239-3248.

Leung CG, Mason P (1998) A physiological survey of medullary raphe and magnocellular reticular neurons in the anesthetized rat. J Neurophysiol 80:1630-1646.

Leung CG, Mason P (1999) Physiological properties of medullary raphe neurons during sleep and waking. J Neurophysiol 81:584-595.

Li YW, Bayliss DA (1998) Presynaptic inhibition by 5-HT1B receptors of glutamatergic synaptic inputs onto serotonergic caudal raphe neurones in rat. J Physiol (Lond) 510:121-134.

Loewy AD, Saper CB, Baker RP (1979) Descending projections from the pontine micturition center. Brain Res 172:533-538.

Lund JP, Rossignol S, Murakami T (1981) Interactions between the jawopening reflex and mastication. Can J Physiol Pharmacol 59:683-690.

Lund JP, Enomoto S, Hayashi H, Hiraba K, Katoh M, Nakamura Y, Sahara Y, Taira M (1983) Phase-linked variations in the amplitude of the digastric nerve jaw-opening reflex response during fictive mastication in the rabbit. Can J Physiol Pharmacol 61:1122-1128.

Mason P (1997) Physiological identification of pontomedullary serotonergic neurons in the rat. J Neurophysiol 77:1087-1098.

Mason P (2001) Contributions of the medullary raphe and ventromedial reticular region to pain modulation and other homeostatic functions. Annu Rev Neurosci 25:737-777.

Masson Jr RL, Sparkes ML, Ritz LA (1991) Descending projections to the rat sacrocaudal spinal cord. J Comp Neurol 307:120-130.

Matos FF, Rollema H, Brown JL, Basbaum AI (1992) Do opioids evoke the release of serotonin in the spinal cord? An in vivo microdialysis study of the regulation of extracellular serotonin in the rat. Pain 48:439-447.

Matsumoto S, Levendusky MC, Longhurst PA, Levin RM, Millington WR (2004) Activation of mu opioid receptors in the ventrolateral periaqueductal gray inhibits reflex micturition in anesthetized rats. Neurosci Lett 363:116-119.

Matsuura S, Downie JW (2000) Effect of anesthetics on reflex micturition in the chronic cannula-implanted rat. Neurourol Urodyn 19:87-99.

Matsuura S, Allen GV, Downie JW (1998) Volume-evoked micturition reflex is mediated by the ventrolateral periaqueductal gray in anesthetized rats. Am J Physiol 275:R2049-R2055.

Mattsson S, Gladh G, Lindstrom S (2003) Relative filling of the bladder at daytime voids in healthy school children. J Urol 170:1343-1346.

McMahon SB, Spillane K (1982) Brain stem influences on the parasympathetic supply to the urinary bladder of the cat. Brain Res 234:237-249.

Murphy AZ, Rizvi TA, Ennis M, Shipley MT (1999) The organization of preoptic-medullary circuits in the male rat: evidence for interconnectivity of neural structures involved in reproductive behavior, antinociception and cardiovascular regulation. Neuroscience 91:1103-1116.

Nadelhaft I, Vera PL (1995) Central nervous system neurons infected by pseudorabies virus injected into the rat urinary bladder following unilateral transection of the pelvic nerve. J Comp Neurol 359:443-456.

Nadelhaft I, Vera PL (1996) Neurons in the rat brain and spinal cord labeled after pseudorabies virus injected into the external urethral sphincter. J Comp Neurol 375:502-517.

Nadelhaft I, Vera PL (2001) Separate urinary bladder and external urethral sphincter neurons in the central nervous system of the rat: simultaneous labeling with two immunohistochemically distinguishable pseudorabies viruses. Brain Res 903:33-44.

Newman DB (1985) Distinguishing rat brainstem reticulospinal nuclei by their neuronal morphology. I. Medullary nuclei. J Hirnforsch 26:187-226.

Noto H, Roppolo JR, Steers WD, de Groat WC (1991) Electrophysiological analysis of the ascending and descending components of the micturition reflex pathway in the rat. Brain Res 549:95-105.

Paxinos G, Watson C (1986) The rat brain in stereotaxic coordinates, Ed 2. San Diego: Academic.

Pescatori M (1999) Urinary retention after anorectal operations. Dis Colon Rectum 42:964

Rocha I, Silva-Carvalho L, Spyer KM (2004) Effect of stimulation of anterior hypothalamic area on urinary bladder function of the anesthetized rat. Clin Auton Res 14:264-269.

Sandkuhler J (1996) The organization and function of endogenous antinociceptive systems. Prog Neurobiol 50:49-81.

Satoh K, Shimuzu N, Tohyama M, Maeda T (1978) Localization of the micturition reflex center at dorsolateral pontine tegmentum of the rat. Neurosci Lett 8:27-33.

Sorkin LS, McAdoo DJ, Willis WD (1993) Raphe magnus stimulation-induced antinociception in the cat is associated with release of amino acids as well as serotonin in the lumbar dorsal horn. Brain Res 618:95-108.

Strack AM, Sawyer WB, Hughes JH, Platt KB, Loewy AD (1989a) A general pattern of CNS innervation of the sympathetic outflow demonstrated by transneuronal pseudorabies viral infections. Brain Res 491:156-162.

Strack AM, Sawyer WB, Platt KB, Loewy AD (1989b) CNS cell groups regulating the sympathetic outflow to adrenal gland as revealed by transneuronal cell body labeling with pseudorabies virus. Brain Res 491:274-296.

Sugaya K, Ogawa Y, Hatano T, Koyama Y, Miyazato T, Oda M (1998) Evidence for involvement of the subcoeruleus nucleus and nucleus raphe magnus in urine storage and penile erection in decerebrate rats. J Urol 159:2172-2176

Sugaya K, Ogawa Y, Hatano T, Nishijima S, Matsuyama K, Mori S (2003) Ascending and descending brainstem neuronal activity during cystometry in decerebrate cats. Neurourol Urodyn 22:343-350.

Taniguchi N, Miyata M, Yachiku S, Kaneko S, Yamaguchi S, Numata A (2002) A study of micturition inducing sites in the periaqueductal gray of the mesencephalon. J Urol 168:1626-1631.

Tattersall JE, Cervero F, Lumb BM (1986) Viscerosomatic neurons in the lower thoracic spinal cord of the cat: excitations and inhibitions evoked by splanchnic and somatic nerve volleys and by stimulation of brain stem nuclei. J Neurophysiol 56:1411-1423.

Valentino RJ, Page ME, Luppi PH, Zhu Y, Van Bockstaele E, Aston-Jones G (1994) Evidence for widespread afferents to Barrington's nucleus, a brainstem region rich in corticotropin-releasing hormone neurons. Neuroscience 62:125-143.

Van Bockstaele EJ, Aston-Jones G, Pieribone VA, Ennis M, Shipley MT (1991) Subregions of the periaqueductal gray topographically innervate the rostral ventral medulla in the rat. J Comp Neurol 309:305-327.

Vizzard MA, Erickson VL, Card JP, Roppolo JR, de Groat WC (1995) Transneuronal labeling of neurons in the adult rat brainstem and spinal cord after injection of pseudorabies virus into the urethra. J Comp Neurol 355:629-640.

Wang W, Tiwari JK, Bradley SR, Zaykin RV, Richerson GB (2001) Acidosisstimulated neurons of the medullary raphe are serotonergic. J Neurophysiol 85:2224-2235.

Watkins LR, Griffin G, Leichnetz GR, Mayer DJ (1980) The somatotopic organization of the nucleus raphe magnus and surrounding brain stem structures as revealed by HRP slow-release gels. Brain Res 181:1-15.

Zhuo M, Gebhart GF (1997) Biphasic modulation of spinal nociceptive transmission from the medullary raphe nuclei in the rat. J Neurophysiol 78:746-758.

Zhuo M, Gebhart GF (2002) Facilitation and attenuation of a visceral nociceptive reflex from the rostroventral medulla in the rat. Gastroenterology 122:1007-1019.

Zhuo M, Sengupta JN, Gebhart GF (2002) Biphasic modulation of spinal visceral nociceptive transmission from the rostroventral medial medulla in the rat. J Neurophysiol 87:2225-2236. 